\title{
Gamificação: ferramenta de potencialização da criatividade no design de serviços
}

\author{
Gamification: Potentialization tool of creativity in the design of services
}

FIGUEIREDO, Luiz Fernando Gonçalves de; Pós-Doutor; UFSC - NAS Design

Iffigueiredo2009@gmail.com

FERREIRA, Alais Souza; Mestranda em Design; UFSC - NAS Design

alais.ferreira@live.com

FIALHO, Francisco Antonio Pereira; Doutor; UFSC

fapfialho@gmail.com

\section{Resumo}

A gamificação deriva diretamente da popularização dos jogos. No design, a gamificação pode auxiliar na simplificação do trabalho ou no processo de aprendizagem durante a procura por soluções. Essa abordagem pode ser vista como um método de resolução de problemas e utilizada para melhorar o envolvimento dos usuários. Assim, objetiva-se identificar as relações entre criatividade, design de serviços e gamificação. Esta pesquisa classifica-se como básica, teórica, qualitativa, exploratória e levantamento bibliográfico de dados secundários, constituída por Revisão Sistemática de Literatura (RSL). Foi utilizado o método Canvas para Bibliometria que se divide em três partes, mas para este artigo será realizada apenas a parte referente à RSL. Como resultado da pesquisa conclui-se que a gamificação pode potencializar a inovação e a criatividade por meio da motivação intrínseca e do engajamento, estes ajudam na resolução de problemas no design de serviço.

Palavras Chave: design de serviço; criatividade; gamificação.

\section{Abstract}

The gamification derives directly from the popularization of the games. In design, gamification can assist in simplifying the work or learning process during the search for solutions. This approach can be seen as a method of troubleshooting and used to improve user involvement. Thus, it is objective to identify the relationships between creativity, service design and gamification. This research is classified as basic, theoretical, qualitative, exploratory and bibliographic survey of secondary data, consisting of systematic revision of the literature (SRL). The Canvas method was used for bibliometrics that is divided into three parts, but for this article will be held only the part pertaining to SRL. As a result of the research it is concluded that gamification can enhance innovation and creativity through intrinsic motivation and engagement, these help in solving problems in service design.

Keywords: service design; creativity; gamification. 


\section{Introdução}

O primeiro estudo formal das crianças no jogo vem do psicólogo russo Lev Vygotsky, cujo estudo da internalização do conhecimento está na vanguarda da aprendizagem em ambientes de jogo. $O$ sucesso de jogos de aprendizagem, tais como Scrabble (jogo de tabuleiro em que se formam palavras) e outros jogos de pensamento acabam por contribuir na formação do usuário, desde sua idade mais precoce.

No passado os mecanismos dos jogos já estavam presentes na forma de viver e se relacionar do ser humano, por isso, não se pode entender a gamificação como algo socialmente novo (NAVARRO, 2013). O termo gamificação foi criado entre 2002 e 2003 por Nick Pelling, ganhando popularidade oito anos depois quando McGonigal (2012) realizou uma apresentação de TED (VIANNA et al., 2013; CASTRO; FERNANDES, 2013). No início do século XX, devido ao surgimento da gamificação, o jogo deixou de ser considerado uma atividade destinada à distração e passou a ser utilizado pelos negócios como uma forma de adquirir conhecimento, desenvolvimento pessoal e profissional.

Assim, a gamificação deriva diretamente da popularização dos jogos e de suas capacidades intrínsecas e extrínsecas de motivar a ação, resolver problemas e potencializar aprendizagens lógicas e/ou criativas nas mais diversas áreas do conhecimento (FORMANSKI, 2016). Na área de design, a gamificação pode auxiliar na simplificação de um trabalho ou no próprio processo de aprendizagem durante a procura por soluções. Olenski (2014) informa que essa abordagem gamificada está encontrando crescente aceitação como um método de resolução de problemas e pode ser utilizada para melhorar o envolvimento dos usuários e de outros importantes indicadores de coleta de dados.

Diante do exposto, questiona-se: Como a gamificação estimula e potencializa a criatividade? Quais características da gamificação contribui para a criatividade no Design de Serviços? Esta pesquisa objetiva identificar as relações entre a criatividade, Design de Serviço e gamificação. Para isso foi necessário, primeiramente, conceituar e descrever as características de cada assunto mencionado; no segundo momento, apontar as relações dessas áreas que foram encontradas nos TCC's, dissertações e teses coletados na Revisão Bibliográfica Sistemática; e na sequência concluir sobre o estímulo de criatividade que a gamificação pode proporcionar para o Design de Serviço.

A pesquisa classifica-se por sua natureza como básica e teórica, pela abordagem como qualitativa, pelos objetivos como exploratória. De acordo com os procedimentos metodológicos o estudo é classificado como levantamento bibliográfico, de dados secundários, constituído pela Revisão Sistemática de Literatura. O método utilizado foi o Canvas para Bibliometria que se divide em três partes, mas para este artigo será realizada apenas a parte referente à Revisão Sistemática.

Esta pesquisa justifica-se, pois, segundo Franke (2015), a imaterialidade do conceito de criatividade tornao amplamente debatido e teorizado nas mais diversas áreas de conhecimento, o que possibilita a inserção de pontes entre áreas afastadas pelo senso comum. $O$ autor ainda informa que a sua pesquisa amplia a possibilidade para uma série de outras pesquisas relacionadas ao tema da criatividade e a sua interface com diversos outros objetos. Machado (2014) e Torquato (2017) propõe para futuras pesquisas o desenvolvimento de estudos e aplicações de técnicas e ferramentas para o despertar da criatividade, o que demonstra a relevância deste artigo.

A criança é criativa e aprende brincando, mas as pesquisas do professor Robinson (2006, 2010) mostram que a escola mata a nossa criatividade uma vez que dentre as pessoas maiores de 25 anos apenas $2 \%$ são criativas. Dessa forma, espera-se concluir que a gamificação pode ser uma ferramenta para despertar nos adultos a criança que existe dentro deles e, consequentemente, potencializar a criatividade em todas as áreas inclusive no Design de Serviço. 


\section{Design de Serviço}

$\mathrm{Na}$ contemporaneidade o reconhecimento da ocorrência de diversidades geográficas, socioculturais e econômicas no Brasil, são fatores que têm evidenciado o Design, posicionando-o como responsável pelo desenvolvimento de projetos de produtos, ambientes e serviços, considerando toda a complexidade e aspectos peculiares às organizações comerciais. Segundo Aros e Figueiredo (2015), o design envolve pesquisas, processos, práticas centradas nas pessoas, e a gestão é um processo sistemático, que define, planeja, desenvolve, implementa e controla ações de design.

Dessa forma, o Designer é o gestor que irá articular essas comunicações, facilitando e apoiando o desenvolvimento de inovações (socioculturais e tecnológicas) no processo de criação de produtos (tangíveis) e serviços (intangíveis). Aros e Figueiredo (2015) apresentam a inovação como uma solução diferenciada que pode ser gerada por contribuições do Design no âmbito social mediante estratégias que podem resultar em benefícios às pessoas e seus modos de produzir e viver.

O Design de Serviço (DS) nos ajuda a inovar, criar novos ou aperfeiçoar serviços, tornandoos mais úteis, usáveis e desejáveis para os clientes, e eficiente bem como eficaz para as organizações. Pode ser considerado um campo holístico, multidisciplinar e integrativo, por conectar as áreas de marketing, design, gestão de empresa e pesquisa de cliente (MORITZ, 2005). Além disso, para a empresa Engine Service Design, o DS projeta melhorias em fatores como a facilidade de usar, satisfação, lealdade e eficiência do serviço ligado às áreas como ambientes, comunicação e produtos - sem esquecer-se das pessoas que entregam o serviço (FRANCISCO, 2016). Complementando essa informação, Stickdorn e Scheneider (2011) destacam cinco princípios para o DS que são: centrado no usuário, co-criativo, sequencial, evidenciado e holístico.

Para Kotler (2005), o serviço é qualquer ato ou desempenho intangível que uma parte possa oferecer a outra, que não resulte na propriedade de nada e que pode ou não estar ligado a um produto. É complicado testar e avaliar as características de um serviço, já que o mesmo não possui forma física, principalmente serviços baseados em complexas interações sociais. Por isso, Brown (2010) propõe que as ideias complexas devem ser materializadas em protótipos. Para o autor, prototipar é dar forma a uma ideia, permitindo aprender com ela, avaliá-la em relação a outras e aperfeiçoá-la. Nesse sentido, o design busca por ferramentas específicas para formulação estratégica, gestão de ideias, modelos e protótipos para inovação, bem como ferramentas de comunicação para ampliar fronteiras (MOZOTA, 2011). A próxima seção aborda a criatividade inclusa nesse contexto de gestão de ideias.

\section{Criatividade}

Segundo Lima e Montenegro ([199-?], p.3), "ser criativo é uma qualidade essencial para qualquer profissional, em qualquer ramo de atividade", mas em algumas profissões essa característica parece ser mais evidente como no caso do Design. Portanto, a criatividade está intrínseca no processo de DS uma vez que solucionar problemas projetuais e gerenciar esse processo é um ofício criativo, por ser uma atitude humana e racional que nem todos os avanços tecnológicos juntos podem substituir. Ainda segundo os autores, entende-se a criatividade como uma habilidade humana básica, em que cada um de nós pode ser criativo (ou mais criativo) se reconhecermos nossos talentos únicos e os desenvolvermos. Essa habilidade depende da psique humana que consiste nos processos psíquicos e está estruturada em "consciente", "inconsciente pessoal" e "inconsciente coletivo" (JUNG, 2000). Esses aspectos são componentes importantes do processo de "individualização", que consiste no ato de ajustar contas consigo mesmo e com a vida (BAIR, 2006). 
O consciente é um sistema do aparelho psíquico que mantém contato com o mundo interior (processos psíquicos internos) e exterior (meio ambiente, sociedade) do sujeito, tendo como núcleo principal o "eu". É na consciência que se destacam os mecanismos de percepção, atenção, memória e raciocínio, por esse motivo as pessoas são conscientes apenas de uma pequena parcela de sua vida psíquica (JUNG, 2000). O inconsciente pessoal é o sistema em que permanecem os conteúdos inconscientes derivados da vida do indivíduo, que geralmente não possuem energia psíquica suficiente para permanecerem no campo da consciência, como: as experiências de vida, os conflitos psicológicos (denominados "complexos") e os desejos pessoais não realizados (JUNG, 2000). No entanto, alguns desses conteúdos podem adquirir energia psíquica suficiente para irromperem na consciência resultando nas lembranças, sonhos e fantasias. $O$ inconsciente coletivo é formado pelas camadas mais profundas do inconsciente e constituído pelos arquétipos, que trazem padrões de comportamento herdados da humanidade desde seu surgimento. Os arquétipos são núcleos instintivos passados de forma psicobiológica de geração a geração (a criança já nasce com ele) (JUNG, 2000).

Conforme Nunes (2010), para Jung o inconsciente pessoal é como a energia que brota das profundezas do inconsciente coletivo, tornando-se uma fonte de criatividade. Portanto, a criatividade de Jung vem do inconsciente pessoal e coletivo. Por isso, para se tornar mais criativo, Lima e Montenegro ([199-?]) sugere que você deve alimentar e aprender a escutar sua "voz" interior, sua intuição. Além disso, é necessário estar aberto a uma variedade de soluções possíveis, sem limitações advindas de sua personalidade, crenças ou cultura social. Outra característica relevante, para o autor, é não ter medo de falhar ou errar, pois até mesmo um resultado ruim, à primeira vista, pode conduzir a uma nova ideia ou nova possibilidade. Lima e Montenegro ([199-?], p.6) finalizam informando que "a criatividade é um estado interior, mas também é um aspecto social da vida". Para Franke, Fialho e Stein (2012) o conceito atual de criatividade é o fruto de um processo de trabalho bem estruturado.

Assim, é relevante conhecer as etapas do processo criativo (Figura 1) para adquirir maior consciência e controle dos caminhos que a mente percorre quando "busca" soluções para um problema.

Figura 1 - Processo criativo
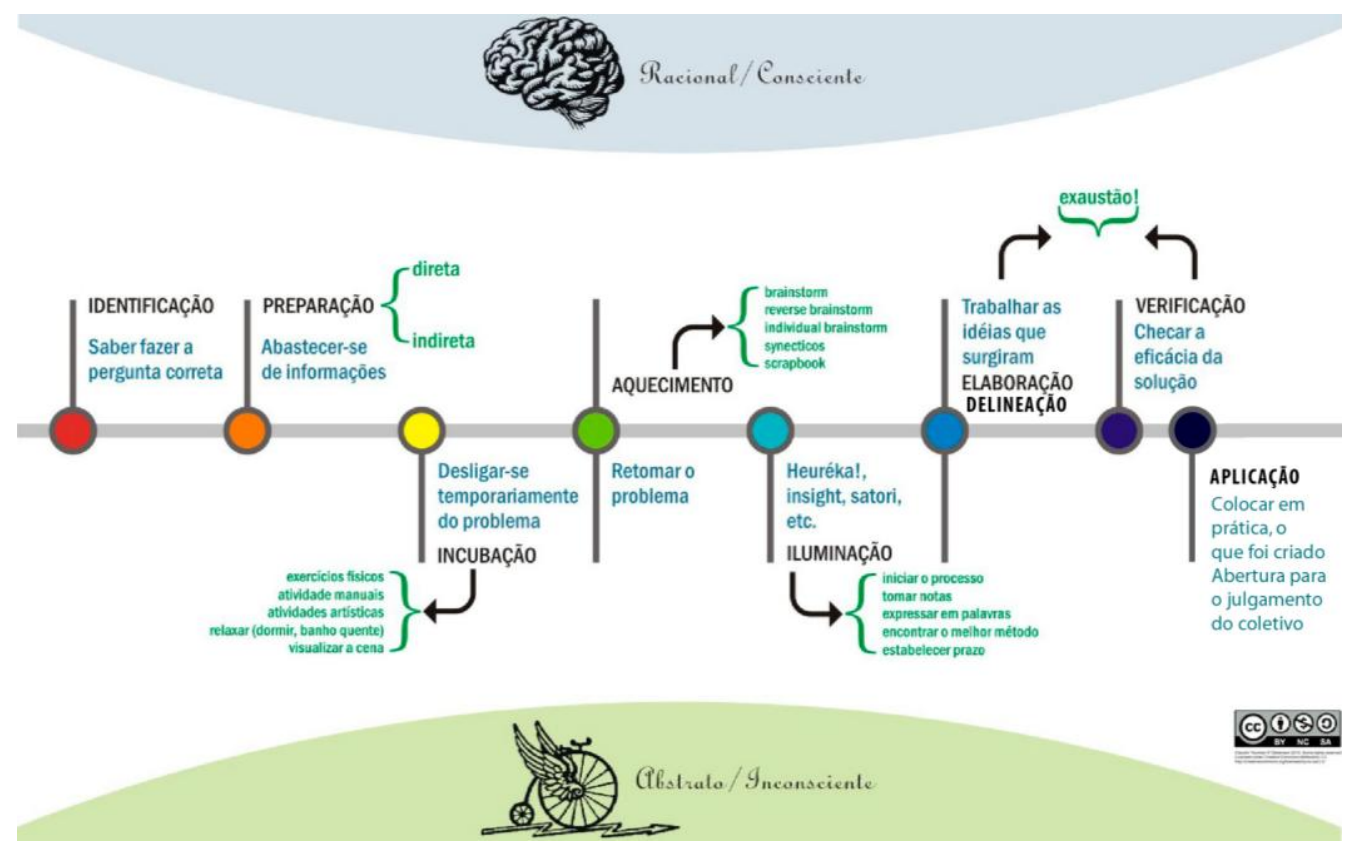

Fonte: Adaptado de Lima e Montenegro ([199-?] 
Portanto, segundo Franke, Fialho e Stein (2012), a criatividade é o processo de gerar novas ideias que tende a ser longo e desgastante, mas acessível a todos. Esse processo passa pela escolha de uma ferramenta adequada, de tempo e esforço para que se fuja do comum. Partindo desse ponto de vista, pode-se citar a gamificação como uma dessas ferramentas que podem potencializar a criatividade, por isso, a próxima seção aborda este conceito.

\section{Gamificação}

Paralelamente à evolução da tecnologia, surgem novos métodos, ferramentas e técnicas que auxiliam as pessoas a solucionarem problemas como o engajamento empresarial ou a colaboração durante o processo criativo de um serviço. De acordo com Formanski (2016), transversalmente a esse avanço, surge o conceito de gamificação que deriva do termo original em inglês gamification. Este pode ser aplicado em qualquer ambiente e corresponde ao uso de mecanismos de jogos orientados ao objetivo de resolver problemas práticos ou de despertar engajamento entre um público específico (VIANNA et al., 2013). Wu (2011) afirma que a gamificação é o uso de atributos de jogo, para conduzir comportamento de jogo em um contexto de não-jogo. Ou seja, é utilizar as teorias, o design, os elementos presentes nos jogos para ajudar na solução de um problema em um contexto que não seja um jogo.

Zichermann (2013) e Zotti e Bueno (2013) informam que a gamificação visa tornar as atividades das mais diversas áreas, como as tediosas e repetitivas, em experiências mais divertidas, interessantes, produtivas e colaborativas. E porque não mais criativas, também? A Gamificação consiste em introduzir diversão, reconhecimento pessoal e/ou competição em atividades normais de trabalho, utilizando técnicas de jogo desenvolvidas com o intuito de atrair, envolver, motivar e engajar os funcionários e todos os envolvidos no processo, ajudando-os a atingir as suas metas (BUNCHBALL, 2010; CAMENISCH, 2012; FORMANSKI, 2016). "O design se caracteriza como uma caixa de ferramentas transformadora inserida no contexto de uma sociedade contemporânea que está em constante processo de mudança, e a gamificação funciona como uma destas ferramentas a disposição do design, visando de alguma forma" simplificar o trabalho ou melhorar o processo dos produtos ou serviços (DALLAGNOL, 2016, p.20).

A gamificação pode ser aplicada em "qualquer contexto comercial no qual se pretende afetar um comportamento específico ou uma mudança estruturada, seja interna ou externamente a um grupo, como em empresas ou grupos de estudo". A pesquisa desse autor está centrada "nas funções que a gestão [de] design desempenha no contexto de desenvolvimento de novos produtos e serviços, e na sua ampla visão do problema e do todo", nesse contexto a gamificação se dá como uma ferramenta para a execução de um eventual problema escolhido (DALLAGNOL, 2016, p.28).

$\mathrm{O}$ ato de jogar apresenta um espaço de criação cultural por excelência, semelhante ao ato de brincar que é uma atividade dotada de significação social que necessita de aprendizagem (DALLAGNOL, 2016; BROUGÈRE, 1998). Nós conseguimos mais motivação e inspiração no mundo dos jogos para colaborar e cooperar, pois quando estamos neste mundo muitos de nós se tornam uma melhor versão de nós mesmos, o mais provável para ajudar na observação de um momento, para lidar com um problema, se levantar após uma falha e tentar novamente (MCGONIGAL, 2012).

A motivação é uma das grandes fontes exploradas pela gamificação. O termo motivação vem da palavra motivus em latim e significa o ato ou efeito de movimentar, ou seja, estar ou ser motivado é ser movido a fazer algo (WERBACH; HUNTER, 2012). "A gamificação não é simplesmente o jogo a ser criado, 
mas sim o método de aplicação de ideias, o processo em si, seja ele de aprendizagem ou não" (DALLAGNOL, 2016, p.37). Esta ferramenta pode ser utilizada no processo de DS buscando atingir um novo método de atender o usuário, de forma que ele aproveite o conteúdo disponibilizado por meio de estratégias utilizadas pelo jogo, buscando motivá-lo e influenciá-lo psicologicamente em suas decisões.

A gamificação tem como objetivo influenciar ou modificar, positivamente, os comportamentos humanos. Por causa disso, esta ferramenta encontra-se fundamentada nos conceitos da psicologia humana e da ciência comportamental baseando-se em três fatores principais (Figura 2): motivação, habilidade e estímulo (DALE, 2014). Para mudar o comportamento humano, estes fatores precisam estar presentes, sendo que a habilidade e a motivação são o equilíbrio para essa mudança.

Figura 2 - Fatores principais da gamificação

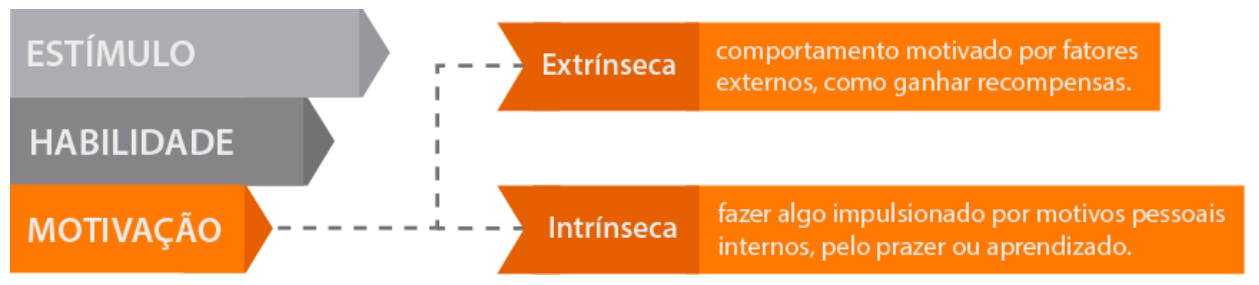

Fonte: Adaptado de Formanski (2016)

Segundo Hardré (2003), a motivação é um fenômeno complexo e um conjunto de interações entre dinâmicas internas, externas, interpessoal e organizacional. Dessa forma, a gamificação pode fornecer experiências atraentes, promovendo aprendizagem e engajamento entre os participantes. Conforme Dorling e Mccaffery (2012), o engajamento ocorre quando o cérebro é premiado e evoca emoções positivas em uma pessoa. Tendo isso em vista, percebe-se que as oportunidades de aplicação da gamificação em empresas vão desde ter clientes mais engajados até permitir a inovação (ERDÕS; KALLÓS, 2014). Portanto, o objetivo da aplicação de jogos no contexto corporativo é: obter alto nível de comprometimento dos funcionários, facilitar a introdução de mudanças na organização e estimular a inovação (VIANNA et al., 2013).

Hu (2003) apresenta a inovação como um processo de produção de conhecimento, exigindo criatividade e envolvendo a incerteza com relação aos resultados. $\mathrm{E}$ um dos quesitos para que haja inovação é o engajamento dos colaboradores, ou seja, ter pessoas mobilizadas em prol da realização de uma causa, para que voluntariamente dediquem seus esforços a um objetivo específico (DUTRA, 2013).

Assim, o principal objetivo da gamificação, inserida como ferramenta no processo de Design de Serviço, pode ser viabilizar uma nova forma de experiência ao praticar o já vivenciado, induzir o estudante, trabalhador ou usuário a ver de maneira diferenciada e divertida as tarefas que deve realizar. A próxima seção apresenta as etapas metodológicas.

\section{Procedimentos Metodológicos}

Esta seção visa apresentar o método utilizado denominado Canvas para Bibliometria, proposto por Medeiros et al. (2015), que divide-se em três partes: revisão sistemática (etapas um a sete); análise bibliométrica (etapas oito e nove); e resultado final (etapa dez). Para este artigo, foi realizado apenas a Revisão Sistemática sobre gamificação, criatividade e design de serviço, inicialmente no repositório da UFSC em setembro de 2017 (Figura 3 e 4). Optou-se por pesquisar 
primeiramente no local de origem dos autores, para mais tarde ampliar a pesquisa para o nível regional, nacional e internacional.

Figura 3 - Revisão Sistemática

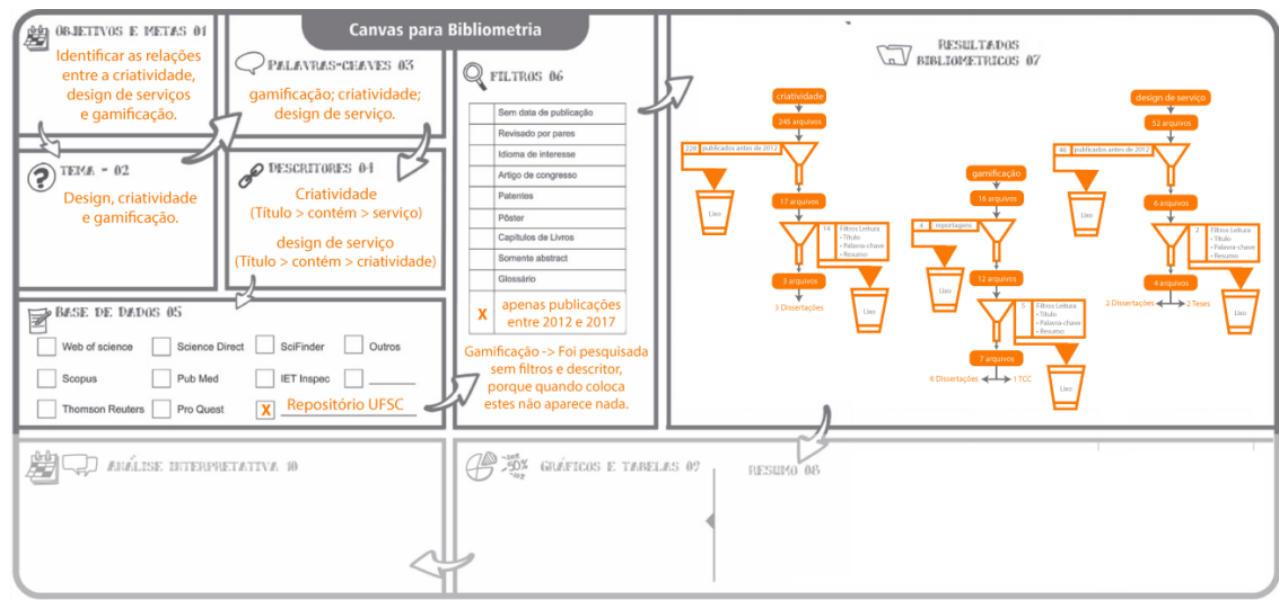

Fonte: Elaborado pelos autores com base em Medeiros et al. (2015)

A sistematização das informações encontradas (etapa sete ilustrada na Figura 3 e 4) está disposta na seção seis que abrange a discussão dos resultados.

Figura 4 - Resultados Bibliométricos ampliado

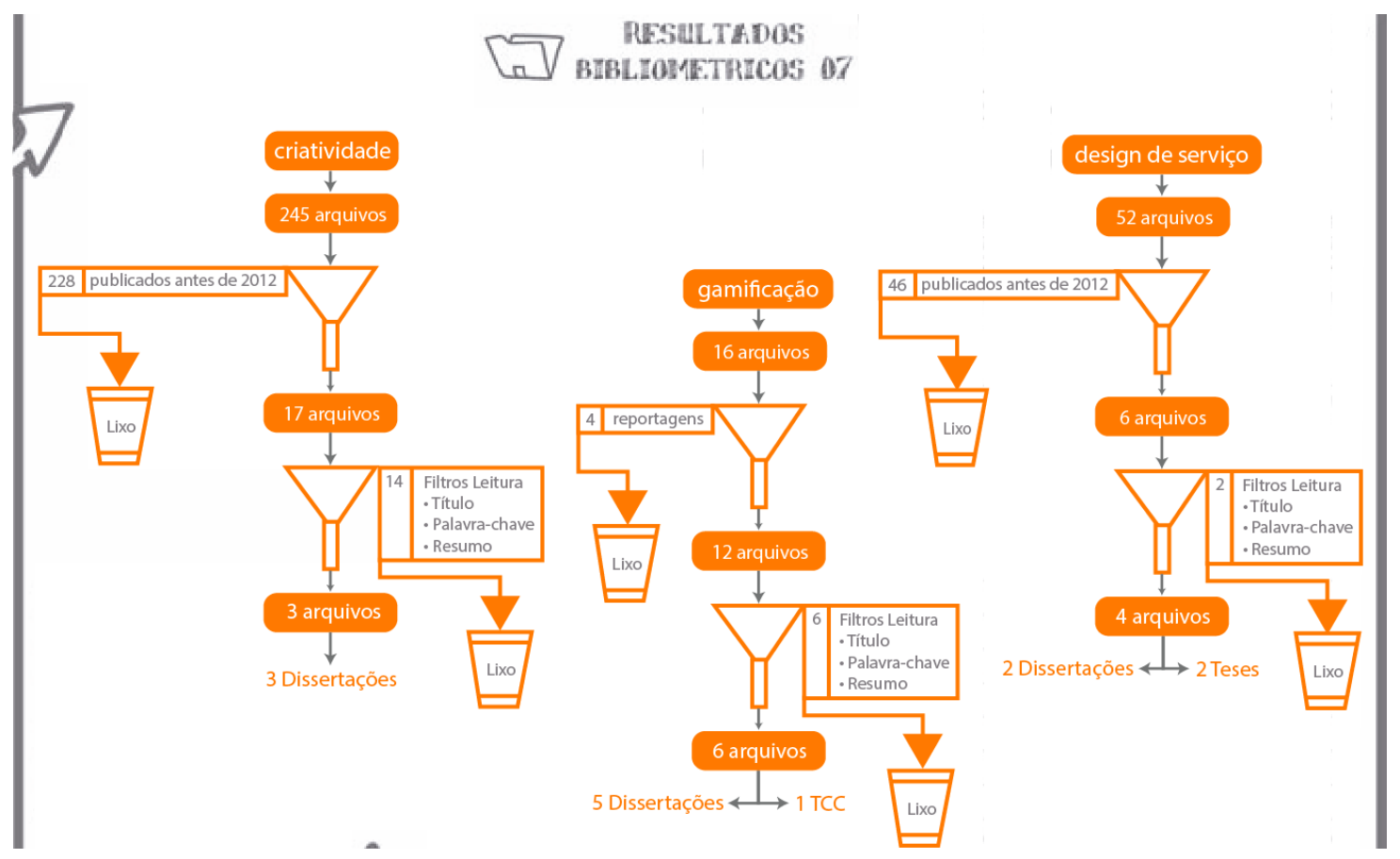

Fonte: Elaborado pelos autores com base em Medeiros et al. (2015)

Este artigo é caracterizado por sua natureza como pesquisa básica e teórica, pela abordagem como qualitativo, pelos objetivos como exploratório por buscar compreender a 
relação entre DS, criatividade e gamificação. De acordo com os procedimentos metodológicos a pesquisa é classificada como Revisão Sistemática de Literatura e levantamento bibliográfico de dados secundários. (GIL, 2010; VIRGILLITO, 2010; CRESWELL, 2016). Os dados encontrados na pesquisa foram apresentados em um quadro que mostra: os títulos, os autores, o ano, as palavraschave e as relações entre as áreas. A próxima seção apresenta a discussão dos resultados.

\section{Resultados}

Essa seção relata a sistematização das informações das pesquisas coletadas na RSL (Quadro 1) e a discussão dos resultados mais relevantes.

Quadro 1 - Identificação e relações com a criatividade, design de serviço e gamificação

\begin{tabular}{|c|c|c|c|c|c|c|c|}
\hline \multirow[t]{2}{*}{ Referência } & \multirow[t]{2}{*}{ Palavras-chave } & \multicolumn{3}{|c|}{ Tipo } & \multirow[b]{2}{*}{ 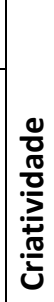 } & \multirow{2}{*}{ 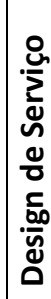 } & \multirow{2}{*}{ 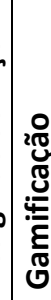 } \\
\hline & & $\underbrace{}_$\[ \]$$ & \text {$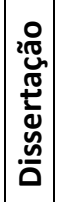 }$ & $\underset{\mathscr{I}}{\mathscr{\Xi}}$ & & & \\
\hline \text {$Torquato (2017) }$ & \text {$Criativo; Criatividade; Conhecimento; Medo. }$ & & & $\mathrm{X}$ & $\mathrm{x}$ & $\mathrm{x}$ & \\
\hline \text {$Pinheiro (2016) }$ & $\begin{array}{l}\text { Inovação; Criatividade; Gestão do Design; Valor; Padrão de Conectividade; } \\
\text { Dinâmica de Rotatividade. }\end{array}$ & & & $\mathrm{x}$ & $\mathrm{x}$ & $\mathrm{X}$ & \\
\hline \text {$Dallagnol (2016) }$ & \text {$Design; Gestão de Design; Gamificação. }$ & & $\mathrm{X}$ & & & & $\mathrm{X}$ \\
\hline \text {$Formanski (2016) }$ & \text {$Gamificação; Empresas; Engajamento; Organização. }$ & & $\mathrm{X}$ & & & $x$ & $\mathrm{X}$ \\
\hline \text {$Richard (2016) }$ & \text {$Modelos de ensino; Gamificação; Microlearning; Plataforma de Gestão de aprendizagem. }$ & $\mathrm{X}$ & & & & $x$ & $\mathrm{x}$ \\
\hline \text {$Bissolotti (2016) }$ & $\begin{array}{l}\text { Gamificação; Elementos dos games; Ambientes virtuais de aprendizagem; } \\
\text { Mídia; Design de interface. }\end{array}$ & & $\mathrm{X}$ & & $x$ & $\mathrm{x}$ & $\mathrm{X}$ \\
\hline \text {$Franke (2015) }$ & \text {$Criatividade; Design; Trabalho; Segregação; Identidade. }$ & & $\mathrm{X}$ & & $\mathrm{x}$ & $x$ & \\
\hline \text {$Machado (2014) }$ & \text {$Criatividade; Inovação; Empresa de Base Tecnológica }$ & & $\mathrm{X}$ & & $\mathrm{x}$ & $\mathrm{X}$ & \\
\hline \text {$Clementi (2014) }$ & \text {$Motivação; Comunidade de Prática; Gamificação. }$ & & $\mathrm{X}$ & & $x$ & $x$ & $\mathrm{X}$ \\
\hline \text {$Zotti (2014) }$ & $\begin{array}{l}\text { Gamificação; Governo 2.0; Engajamento; Elementos de jogos. Engenharia } \\
\text { e Gestão do Conhecimento. }\end{array}$ & & $\mathrm{X}$ & & & & $\mathrm{X}$ \\
\hline \text {$Rossi (2012) }$ & \text {$Gestão decompetências; Senviços de informação; Biblioteca Universitária; Gap de competências. }$ & & $\mathrm{X}$ & & $\mathrm{x}$ & $x$ & \\
\hline \text {$Pintro (2012) }$ & $\begin{array}{l}\text { Serviços; Qualidade em serviços; Serviço de referência; Competências; Processo de } \\
\text { referência tradicional; Processo de referência educativo; Biblioteca universitária. }\end{array}$ & & $x$ & & $x$ & $x$ & $x$ \\
\hline $\begin{array}{l}\text { Menegatti } \\
(2012)\end{array}$ & $\begin{array}{l}\text { Serviços de informação; Bibliotecas universitárias - Acessibilidade; } \\
\text { Bibliotecas universitárias - Deficientes visuais. }\end{array}$ & & $x$ & & $x$ & $x$ & \\
\hline
\end{tabular}

Fonte: Elaborado com base nos autores citados 
Os dados das referências foram exportados para o Excel, e a partir desse programa as imagens abaixo foram geradas (Figuras 5 e 6 ).

Figura 5 - Evolução das publicações ao longo dos anos (à direita) e Documentos por área de conhecimento (à esquerda)
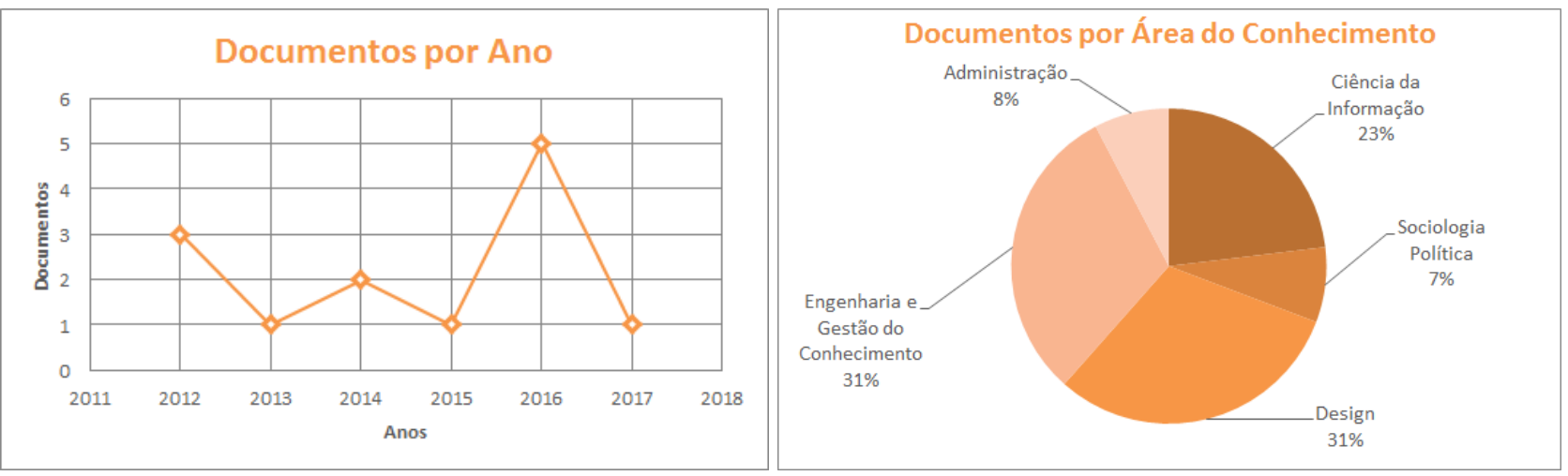

Fonte: Elaborado com base nos autores citados

Figura 6 - Documentos por grupo de pesquisa

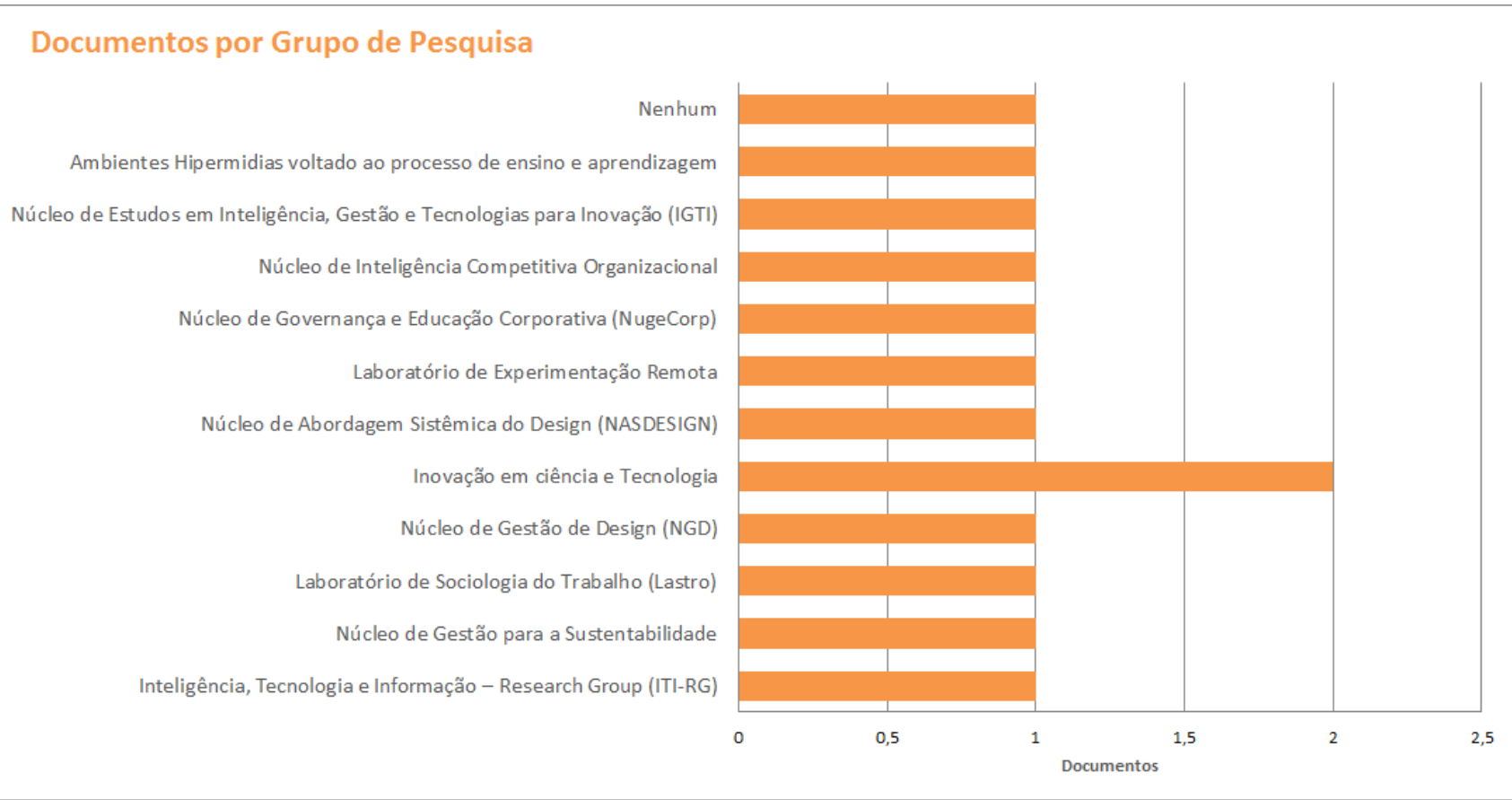

Fonte: Elaborado com base nos autores citados

A Figura 7 apresenta a visualização das relações identificadas no Quadro 1. 
Figura 7 - Relações entre criatividade, design de serviço e gamificação

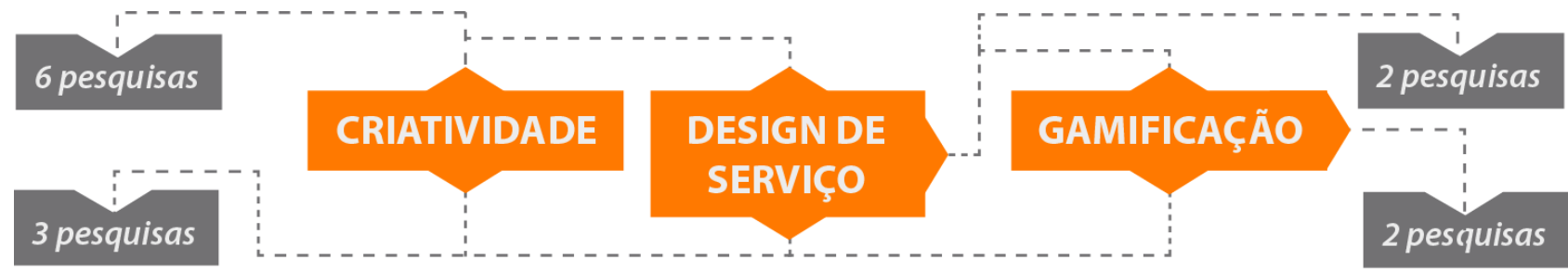

Fonte: Elaborado com base nos autores citados

A partir da extração dos dados, foi possível identificar alguns aspectos relevantes que auxiliam na compressão das relações existentes entre as áreas mencionadas. Pintro (2012) aborda sobre a gamificação de forma subjetiva ao relatar que a criatividade e a motivação são competências necessárias no desenvolvimento de serviços. Isto remete ao mencionado por Aros e Figueiredo (2015) ao informar que o processo de design demanda a participação e o comprometimento de todos os membros da organização, incluindo o usuário; e que o Designer é o gestor que articula essas comunicações, facilitando e apoiando o desenvolvimento de inovações no processo de criação de produtos (tangíveis) e serviços (intangíveis). Nesta articulação das comunicações, que o Designer deve estar disposto em realizar, está inclusa a motivação de todos os envolvidos.

Dessa forma, menciona-se a dissertação de Clementi (2014) que tem como objetivo propor diretrizes motivacionais, com base na investigação de como a motivação impacta as comunidades e como influência o comportamento dos indivíduos e por fim, como a gamificação pode ser utilizada para motivar os membros das Comunidades de Práticas (CoPs). O autor destaca que a teoria da gamificação proporciona benefícios na gestão de pessoas, já que é formada por um conjunto de teorias motivacionais que permeiam os elementos de jogos e tem potencial para motivar as pessoas. Clementi (2014, p. 129-130) observou "que os elementos fundamentais das CoPs - domínio, comunidade e prática - tem uma essência motivadora, pois se referem aos elementos centrais da motivação intrínseca - autonomia, relacionamento e competência" - que contribui para resultados positivos como a criatividade, o desempenho e a persistência na tarefa. $\mathrm{O}$ autor verificou que uma das características mais importantes e vantajosa das CoPs é o desenvolvimento de uma prática com base nos conhecimentos compartilhados, pois além das redes sociais e do aprendizado coletivo, estas produzem resultados práticos como inovação de produtos, serviços e procedimentos internos.

A pesquisa realizada por Bissolotti (2016) complementa a anterior, pois informa que nos últimos anos houve maior inclusão da gamificação em diversas áreas para motivar e engajar pessoas por meio da criatividade. Para isso, as metas da experiência de usuário e do design centrado no ser humano preocupam-se em explicar o comportamento que o jogador ou usuário tem a partir de sua experiência (tanto desejáveis quanto indesejáveis), que inclui todas as crenças, preferências, emoções, comportamento e repostas físicas durante a utilização dos games ou serviços. A dissertação de Bissolotti (2016) sistematizou recomendações para a utilização dos elementos da gamificação em práticas projetuais de ambientes virtuais de aprendizagem. Essas recomendações são um conjunto de instruções e indicações que devem ser consideradas em todas as fases da prática projetual em ambientes virtuais de aprendizagem gamificada, com o intuito de possibilitar um maior alcance nos níveis de estruturação de processos de design. O autor identificou que os principais elementos gamificados são aqueles diretamente associados à experiência do usuário no sistema. Bissolotti (2016) também evidencia que ao mensurar a motivação é possível identificar que a aprendizagem dos 
usuários, independentemente do nível de ensino, requer estímulos no sentido de que suas necessidades sejam atendidas, o que poderá resultar em motivação intrínseca, extrínseca ou desmotivação, estando ou não em um estado de fluxo. Essas constatações condizem com o exposto pelos autores Werbach e Hunter (2012), Dale (2014), Formanski (2016) e Hardré (2003), pois estes relatam que a gamificação está fundamentada nos conceitos da pscicologia humana e da ciência comportamental e, com isso, possui três pilares principais: a motivação (extrínseca e intrínseca), a habilidade e o estímulo. Os autores ainda mencionam que a habilidade e a motivação são os pilares que auxiliam no equilíbrio da mudança do comportamento humano. Nesse sentido, Formanski (2016) relata que quando as pessoas são motivadas intrinsecamente conseguem ver sentido no que estão fazendo, prestam mais atenção nos detalhes, visualizam mais possibilidades para resolver os problemas e tornam-se mais criativas.

Assim, ressalta-se a pesquisa de Franke (2015) que tem como objetivo analisar como se dão as relações de trabalho em uma empresa de tecnologia, verificando de que forma a produção criativa se apresenta e se posiciona tanto nas práticas dos trabalhadores criativos quanto nas dos gestores. Neste sentido, o autor afirma que devido ao empreendedorismo, a criatividade e inovação tornam-se quesitos diferenciais para determinar o sucesso ou o fracasso profissional, ampliando o consumo de bens para o consumo de serviços (experiências). Por isso, Franke (2015) percebe as empresas como uma rede que já não vende exclusivamente produtos, mas também vende e compra serviços. É interessante que quando o autor questiona os entrevistados sobre o que é ser alguém criativo, estes respondem:

\begin{abstract}
Talvez esse ponto de não ter medo de errar. Uma pessoa criativa é aquela que expõe as ideias sem medo, sem receio de represália ou algo do tipo. Porque eu não acredito que criatividade seja algo exclusivo de algumas pessoas, acho é que algumas pessoas 'matam' o criativo. Porque todo mundo é criativo quando criança e a criatividade vai sendo lapidada à medida que a gente cresce, [...] deixa de ser exercida. Na nossa profissão de designer, a gente é convidado a exercer isso o tempo todo, por isso, quem sabe, podemos dizer que designer, e outras profissões, são mais criativas que outras. Mas não por uma questão de natureza. [...] Criatividade é quando você se arrisca mesmo a algo novo. (FRANKE, 2015, p. 100).
\end{abstract}

Uma criança pode ser criativa quando os "por quês?" dominam seus discursos, questionando a validade da normatividade. Dessa forma, o autor acredita que "matamos" o criativo não pelo desuso, mas pela aceitação do que acreditamos ser a realidade. Então, Franke (2015) afirma que questionar e formular respostas próprias está na base do que é criativo para os entrevistados. $O$ autor também informa que a criatividade como repertório está situada em uma zona ambígua entre o coletivo (porque é alimentada por experiências resultantes da interação entre o indivíduo e o que o cerca - sejam objetos, situações ou pessoas) e o individual (porque todo o acumulo de informações que formam o repertório é decorrente das próprias decisões e vontades). O pensamento deste autor condiz com a visão de Lima e Montenegro ([199-?]), Jung (2000), Bair (2006), Nunes (2010) e Franke, Fialho e Stein (2012) que entendem a criatividade como uma habilidade humana básica de cada indivíduo que pode ser potencializada se este reconhecer os seus talentos únicos e os desenvolver. Além disso, para Jung (2000) e Bair (2006), essa habilidade depende da psique humana que consiste nos processos psíquicos entre o consciente, inconsciente pessoal e inconsciente coletivo (componentes importantes do processo de individualização). Neste sentido, Lima e Montenegro ([199-?]) sugerem que é necessário estar aberto a uma grande variedade de soluções possíveis, sem limitações advindas de sua personalidade, crenças ou cultura social; e não ter medo de falhar ou errar, pois esses resultados ruins podem conduzir a uma nova ideia, ampliando as possibilidades. 
Na visão de Machado (2014), a criatividade visando à inovação de produtos ou serviços precisa de gestores atentos e conscientes de que o processo e estímulo criativo acontecem a partir do momento que ferramentas e estratégias de ação são oferecidas aos colaboradores. Essas ferramentas e estratégias ajudam a captar a experiência individual dos colaboradores e transformá-las em um ativo institucional por meio da transmissão de lições aprendidas, convertendo-as em ações eficazes na busca de novas soluções. A partir disso, o autor caracterizou ações que estimulam o potencial criativo, tais como: liberdade para criar, possibilidade de expor novas ideias, motivação e satisfação na execução das atividades, incentivo dos líderes e dos colegas de trabalho, formalização nos processos de desenvolvimento de produto ou serviço e espaço para criação. Uma dessas ferramentas pode ser a gamificação, juntamente com a aplicação de suas técnicas, elementos e mecânicas como mencionado na fundamentação teórica pelos autores Vianna et al. (2013), Wu (2011), Zichermann (2013), Zotti e Bueno (2013), Bunchball (2010), Camenisch (2012), Formanski (2016) e Dallagnol (2016).

Por este motivo, torna-se relevante mencionar a pesquisa de Torquato (2017) que propõe ações direcionadas ao desenvolvimento do potencial criativo e que potencializam a confiança criativa frente ao medo, são elas: 1) Criar espaço cognitivo descontraído, aconchegante e acolhedor; 2) Oferecer cursos de capacitação; 3) Possibilitar abordagens centradas no ser humano, como o Design Thinking, Socioterapia, Biodanza, Psicodrama, Jogos Teatrais, Eneagrama e Arteterapia; 4) Promover a comunicação; 5) Incentivar e promover atividades físicas; 6) Incentivar a leitura e debates sobre temas de filmes relacionados ao autoconhecimento e medo; 7) Proporcionar atividades para o contato com Mente, Corpo e Espírito; e 8) Realizar atividades lúdicas. Essas sugestões exigem mudanças no comportamento e na cultura das pessoas, mas principalmente no contexto organizacional, pois sendo os colaboradores capitais intelectuais organizacionais se faz necessário que sejam estimulados a expressar seu talento no ambiente interno para que a criatividade possa florescer. Também existe a necessidade do autoconhecimento, pois é por meio deste que vai acontecer o processo de desconstrução para a construção de novos conhecimentos, habilidades e atitudes. Assim, automaticamente, vai gerar a confiança necessária para geração de novas ideias, surgimento da criatividade e consequente inovação nos processos, produtos ou serviços organizacionais.

A gamificação pode auxiliar nessas mudanças do comportamento, já que segundo Formanski (2016) a aplicabilidade da gamificação gera mudanças positivas no processo como o maior engajamento dos envolvidos no processo gamificado, pois este tem como objetivo influenciar positivamente os comportamentos humanos. Diante do exposto, parte-se para a próxima seção em que serão relatadas as considerações finais desta pesquisa.

\section{Considerações Finais}

Retomando os questionamentos feitos no início da pesquisa, "Como a gamificação estimula e potencializa a criatividade? Quais características da gamificação contribui para a criatividade no design de serviços?", conclui-se que a gamificação surge como uma ferramenta que pode potencializar a criatividade em adultos por meio de processos inclusos nos games. Além disso, esta também pode auxiliar os designers na motivação, engajamento e a libertar a criança que existe dentro deles durante o processo de criação ou cocriação de um produto ou serviço.

Esta pesquisa objetivou identificar as relações entre a criatividade, o design de serviço e a gamificação. Para isso, primeiramente, foi conceituado e descrito as características de cada assunto mencionado nas seções referentes à fundamentação teórica; no segundo momento, foi apontado na 
seção de resultados as relações entre as áreas de Criatividade, Design de Serviço e Gamificação, que foram encontradas nos TCC's, dissertações e teses coletados na RSL; e finaliza-se ao apresentar abaixo (nesta seção) as considerações finais relativas ao estimulo de criatividade que a gamificação pode proporcionar para o design de serviço.

A autora Mcgonigal (2012) informa que quando estamos no mundo dos jogos muitos se tornam a melhor versão de si mesmos para ajudar na observação de um momento, para resolver um problema, para se levantar após uma falha e tentar novamente. Isso vai de encontro com o que Jung diz sobre os arquétipos, em que dentro de nós existem diversas personas, diversos eus, a gamificação permite liberar a melhor persona, além de impulsionar a tentar novamente perante alguma falha contribuindo para a criatividade, que nada mais é que errar e tentar novamente até acertar e conseguir a melhor solução para o problema.

De acordo com o que Dale (2014) relatou, a gamificação influencia nas mudanças de comportamentos humanos. Essas mudanças podem colaborar não apenas na motivação, mas também para potencializar a criatividade. Formanski (2016) completou ao informar que pessoas motivadas intrinsecamente percebem mais possibilidades para solucionar um problema e são mais criativas. Com isso, conclui-se que a gamificação estimula a criatividade por meio da motivação intrínseca.

Ressalta-se, ainda, que os autores Erdõs e Kallós (2014) e Dallagnol (2016) abordam que a gamificação estimula a inovação, e Hu (2003) informa que a inovação exige criatividade e engajamento dos colaboradores. Ao considerar que a inovação e a criatividade estão interligadas, conclui-se: que se a gamificação pode estimular a inovação, ela também pode estimular a criatividade; e que a inovação está presente dentro das empresas de serviços (design de serviço), que exige criatividade e engajamento dos funcionários, exigências essas que são proporcionadas pela gamificação. Portanto, conclui-se que a gamificação potencializa a criatividade por meio da motivação e do engajamento, estes ajudam na resolução de problemas no design de serviço.

Como limitação de pesquisa, ressalta-se que devido à alta complexidade de processar informações de documentos extensos (como dissertações e teses), pesquisou-se primeiramente no Repositório UFSC (local de origem dos autores), para mais tarde ampliar a pesquisa ao incluir outras bases de dados a nível nacional e internacional. Isto acaba por tornar-se uma oportunidade para futuras pesquisas.

\section{Referências}

AROS, K. C.; FIGUEIREDO, L. F. G. 2015. Gestão de design para inovação social: uma possível relação. In: IDEMI, 4., 2015, Florianópolis. Anais da Fourth International Conference on Integration of Design, Engineering and Management for innovation. Florianópolis: UDESC, 2015.

BAIR, D. Jung: uma biografia. v. 1. Globo Livros, 2006.

BROUGÈRE, G. Jogo e educação. Porto Alegre: Artes Médicas, 1998.

BROWN, T. Design thinking: uma metodologia ponderosa para decretar o fim das velhas ideias. Rio de Janeiro: Elsevier, 2010.

BUNCHBALL, Inc. Gamification 101: An Introduction to the Use of Game Dynamics to Influence Behavior. 2010. (http://www.bunchball.com/gamification gamification101.pdf)

BISSOLOTTI, K. Recomendações de elementos gamificados em práticas projetuais para ambientes virtuais de aprendizagem. Dissertação (mestrado) - Centro de Comunicação e Expressão, Programa de Pós-Graduação em Design, Universidade Federal de Santa Catarina, Florianópolis, 2016. 
CAMENISCH, J. Make It a Game: Using Gamification to Build Your Business. 2012. (https://www.upwork.com/blog/2012/01/make-it-a-game-using-gamification-to-build-your-business/)

CASTRO, F. S.; FERNANDES, A. M. da R. Aprendendo química orgânica através de gamificação. Anais do Computer on the Beach, 2013, p. 328-330.

CLEMENTI, J. A. Diretrizes motivacionais para comunidades de prática baseadas na gamificação. Dissertação (Mestre em Engenharia e Gestão do Conhecimento) - Programa de Pós-Graduação em Engenharia e Gestão do Conhecimento, Universidade Federal de Santa Catarina, Florianópolis, 2014.

CRESWELL, J. W. Projeto de pesquisa: métodos qualitativo, quantitativo e misto. Porto Alegre: SAGE, 2010.

DALLAGNOL, V. A inserção da gamificação no processo de gestão de design. Dissertação (mestrado) - Centro de Comunicação e Expressão, Programa de Pós-Graduação em Design, Universidade Federal de Santa Catarina, Florianópolis, 2016.

ERDÕS, Erenc; KALLÓS, Gábor. Benefit Evaluation Model for Gamified Add-Ons in Business Software. Acta Polytechnica Hungarica, p. 109-124, 2014.

FRANCISCO, P. H. D. Avaliação estética de protótipos no design de serviço. 2016. Dissertação (Mestrado em Design) - Setor de Artes, Comunicação e Design da Universidade Federal do Paraná, Curitiba, 2016.

FRANKE, F. A.; FIALHO, F. A. P.; STEIN, M. Coordenação de equipes criativas. In: IDEMI, 2., 2012, Florianópolis. Anais da Fourth International Conference on Integration of Design, Engineering and Management for innovation. Florianópolis: UDESC, 2012.

FRANKE, F. A. A domesticação de Pandora: a criatividade como "ferramenta" de trabalho. Dissertação (mestrado) - Centro de Filosofia e Ciências Humanas, Programa de Pós-Graduação em Sociologia Política, Universidade Federal de Santa Catarina, Florianópolis, SC, 2015.

HARDRÉ, P. L. Human Performance Technology Beyond Two Decades of Motivation: a review of the research and practice in instructional design and human performance technology. Human Resource Development Review, v. 2, n. 54, 2003.

HU, A. R\&D Organization, monitoring intensity and innovation performance in Chinese industry. Econ. Innov. New Techn., v. 12, 2003.

Os arquétipos e o inconsciente coletivo. Petrópolis, RJ: Vozes, 2000.

DALE, S. Gamification: making work fun, or making fun of work? Business Information Review, p. 82-90, jun. 2014.

DORLING, A.; MCCAFFERY, F. The Gamification of SPICE. Software Process Improvement and Capability Determination Communications in Computer and Information Science, v. 290, 2012.

DUTRA, J. A inovação empresarial depende do engajamento das pessoas. 2013. (http://www.senior.com.br/ainovacao-empresarial-depende-do-engajamento-das-pessoas/\#sthash.ZTT4MnVw.LNRAwnQa.dpuf)

FORMANSKI, F. N. Aplicabilidade da gamificação no contexto empresarial. Dissertação (mestrado) Centro Tecnológico, Programa de Pós-Graduação em Engenharia e Gestão do Conhecimento, Universidade Federal de Santa Catarina, Florianópolis, 2016.

\section{GIL, A. C. Como elaborar projetos de pesquisa. São Paulo: Atlas, 2010.}

KOTLER, P. Administração de Marketing. São Paulo: Prentice Hall, 2005.

LIMA, J. A. de A.; MONTENEGRO, G. N. Apostila: disciplina de criatividade. Campina Grande: Universidade Federal de Campina Grande, [199-?].

MACHADO, E. V. Criatividade e Inovação: Um Estudo de Caso em Uma Empresa de Base Tecnológica. Dissertação (Mestrado) - Centro Tecnológico, Programa de Pós-Graduação em Engenharia e Gestão do Conhecimento, Universidade Federal de Santa Catarina, Florianópolis, SC, 2014.

MCGONIGAL, J. Realidade em jogo: por que os games nos tornam melhores e como eles podem mudar o mundo. Rio de Janeiro: Best Seller, 2012. 
MEDEIROS, I. L. de et al. Revisão Sistemática e Bibliometria facilitadas por um Canvas para visualização de informação. Revista Brasileira de Design da Informação, v. 12, n. 1, 2015, São Paulo, p. 93-110.

MENEGATTI, Y. Serviços de informação acessíveis para deficientes visuais em bibliotecas de instituições de ensino superior no município de Florianópolis/SC. Dissertação (Mestrado em Ciência da Informação) - Programa de Pós-Graduação em Ciência da Informação, Universidade Federal de Santa Catarina, Florianópolis, 2012.

MORITZ, S. Service Design: practical access to an evolving fiel. London: Köln International School of Design, 2005.

MOZOTA, B. B. de. Gestão do design: usando o design para construir o valor de marca e inovação corporativa. Porto Alegre: Bookman, 2011.

NAVARRO, G. Gamificação: a transformação do conceito do termo jogo no contexto da pós-modernidade. 2013. (http://200.144.182.130/celacc/sites/default/files/media/tcc/578-1589-1-PB.pdf)

NUNES, L. Ponte para Terabítia: análise junguiana do processo de individuação através da fantasia de uma obra cinematográfica. Tese (Doutorado) - Faculdade de Psicologia, Universidade do Extremo Sul Catarinense, Criciúma, 2010.

OLENSKI, Steve. How to Solve with Gamification. 2014. (http://www.forbes.com/sites/steveolenski/2014/03/05/how-to-solve-your-biggest-marketing-problems-with-gamification/)

PINHEIRO, I. R. Criatividade e gestão da inovação contínua em design: uma proposta metodológica. Tese (Doutor em Design) - Programa de Pós-graduação em Design, Universidade Federal de Santa Catarina, Florianópolis, 2016.

PINTRO, S. Serviço de referência em bibliotecas universitárias: um estudo de competências e qualidade. Dissertação (Mestrado em Ciência da Informação) - Programa de Pós-Graduação em Ciência da Informação, Universidade Federal de Santa Catarina, Florianópolis, 2012.

RICHARD, T. C. Aplicação de Gamificação e Microleaming: um aprimoramento na plataforma de gestão de aprendizagem da IMAGINARIUM. TCC(Graduaçãoe em Administração)-Centro Sócio Econômico, UniversidadeFederal deSanta Catarina, Florianópolis, 2016.

ROBINSON, S. K. Será que as escolas matam a criatividade? 2006. (https://www.ted.com/talks/ken_robinson_says_schools_kill_creativity?language=pt-br\#t-178793)

“A escola mata a criatividade”. 2010. (https://istoe.com.br/81169_A+ESCOLA+MATA+A+CRIATIVIDADE+/)

ROSSI, T. Gestão de competências na prestação de serviços de informação em bibliotecas de universidades da região de Florianópolis/SC. Dissertação (Mestrado em Ciência da Informação) - Programa de Pós-Graduação em Ciência da Informação, Universidade Federal de Santa Catarina, Florianópolis, 2012.

STICKDORN, M.; SCHENEIDER, J. This is service design thinking: basics, tools, cases. Amsterdan: Wiley, 2012.

TORQUATO, M. O Despertar da Criatividade: Gerenciando o medo. Tese (doutorado) - Centro Tecnológico, Programa de Pós-Graduação em Engenharia e Gestão do Conhecimento, Universidade Federal de Santa Catarina, Florianópolis, SC, 2017.

VIANNA, Y. et al. Gamification, Inc: como reinventar empresas a partir de jogos. Rio de Janeiro: Mjv Press, 164 pp., 2013.

VIRGILLITO, S. B. Pesquisa de marketing: uma abordagem quantitativa e qualitativa. São Paulo: Saraiva, 2010.

WERBACH, K.; HUNTER, D. For the Win: How Game Thinking Can Revolutionize Your Business. Wharton Digital Press, 2012.

WU, M. Gamification from a Company of Pro Gamers. Lithium Technologies Inc. 2011. (http://ithosphere.lithium.com/t5/Building-Community-the-Platform/Gamification-from-a-Company-of-Pro-Gamers/ba-p/19258)

ZICHERMANN, G. The Gamification Revolution. O'Reilly Media, 2013.

ZOTT, A. I.; BUENO, T. C. D'A. Gamificação para o fortalecimento da cidadania. In: 42 JAllO - SIMPOSIO SOBRE LA SOCIEDAD DE LA INFORMACION, 2013. Anales. Mar del Plata, 2013, p. 341-364. (http://42jaiio.sadio.org.ar/proceedings/simposios/Trabajos/SSI/21.pdf)

ZOTTI, A. I. Engajamento de gestores públicos e cidadãos através de uma métrica baseada em elementos de gamificação. Dissertação (mestrado) - Centro Tecnológico, Programa de Pós-Graduação em Engenharia e Gestão do Conhecimento, Universidade Federal de Santa Catarina, Florianópolis, 2014. 